\title{
A Warming System Compounded with Biogas and Waste Heat from Industrial Boiler's Flue Gas or Solar Energy
}

\author{
Zilong Zhang \\ School of North China Electric Power University, Baoding 071000, China \\ 1406915672@qq.com
}

Keywords: biogas; solar energy; the flue gas; the warming system.

\begin{abstract}
In order to promote the development of biogas project in cold northern rural areas, this paper introduces some details about a set of warming system compounded with biogas and the waste heat from industrial boiler's flue gas or solar energy , which can makes the biomass fermented normally even if the weather is so cold that the reaction is slow. Facing to the problem of the unreasonable use in waste heat of industrial boiler's flue gas, the warming system provides a reasonable way to utilize. Compared with the effect of raising temperature and the heat loss in biogas system, the warming system can ensure the stable operation of the biogas project. This paper can provide a reference to the construction of supporting facilities in biogas warming system in cold northern rural areas.
\end{abstract}

\section{Existing problems in utilization of biogas in the rural area}

Currently, there is a "South More-North Little" imbalance of biogas development in rural areas. In terms of production and consumption, biogas used in North China is significantly less than South China. Biogas utilization differences between the North and South is fundamental temperature difference. Studies have found that fermentation of biogas can be divided into 3 stages, the fermentation at room temperature $10 \sim 26{ }^{\circ} \mathrm{C}$, the medium temperature zone in $28 \sim 38{ }^{\circ} \mathrm{C}$ (the optimum temperature is 35 degrees centigrade), $46 \sim 60^{\circ} \mathrm{C}$ is the high fermentation temperature zone. In these three temperature zones, fermentation gas can be produced. In this temperature range, the higher the temperature is, the more active the microbial activity is, the more the gas production is. Microorganisms are very sensitive to temperature changes, temperature suddenly rise or fall will affect the microbial life to cause the deterioration of the gas-production quantity. Temperatures on both North-South differences, in the utilization of biogas in the North area, there is the question that the rate of gas production will fall sharply in winter affecting the utilization of biogasseriously.

\subsection{Biogas Insulation System Design}

In the cold weather of northern China, biogas fermentation tank's heat radiates quickly, so we need to make insulation for it. There are many existed insulation measures. Large and middle scale biogas engineering mainly uses fossil fuel hot water boiler, biogas, solar, biogas power generation and waste heat utilization to heat and so on. Currently rural areas in the north China, there are many small rural enterprises in which the waste heat from boiler fuel gas alwayscan'ttake a good use so as to cause much waste. So as for the thermal insulation in rural small and medium scale biogas engineering, one way is combining the waste heat from boiler fuel gas in small rural enterprises with the solar energy tomake thermal insulation of biogas tanks. 


\section{Research Content}

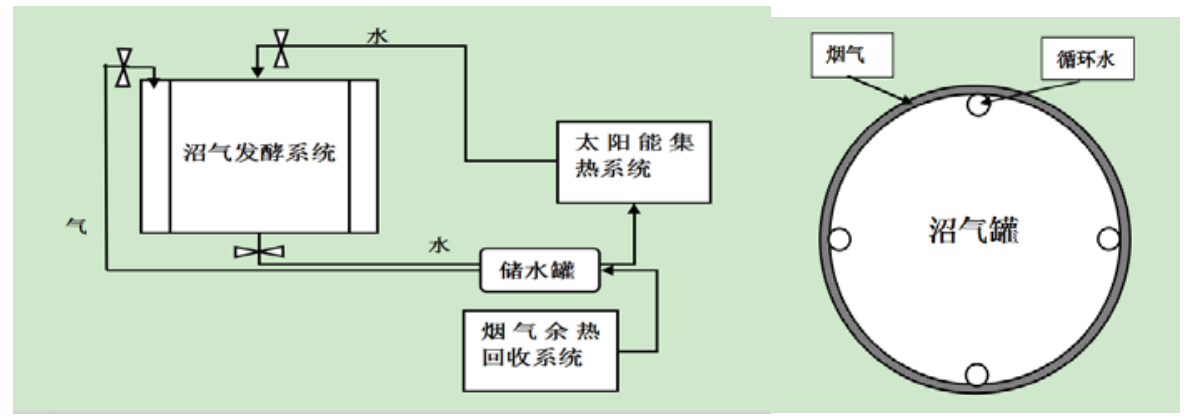

Figure 1 solar and rural coal stove flue gas Figure 2the fuel gas will flow heat composite biogas warming system into again into the casing

Just as Figure 1 illustrated, solar and rural coal stove flue gas heat composite biogas warming system is divided into solar collecting hot system, fuel gas heat recycling system and biogas generation system. Solar collecting hot system heats the water in storage pitcher through the heat collection from solar collectors. In the close outside wall of biogas tank, it layouts four root pipelines which pass into water heated by solar and flue gas. The hot water exchanges heat with fermentation raw materials through radiation and convection way, which makes biogas fermentation system keeping within a moderate fermentation temperature range. Temperature system uses temperature sensor for automatic temperature control and when the temperature of solar heated hot water is below the room temperature heating zone, it will close water valves to prevent water cooling from gas tank. Similarly, when the temperature is higher than high-temperature fermentation area, it has to close the water valve to prevent the high temperature of tank. Fuel gas heat recycling system will concentrate exhaust produced by boiler and exhaust first passes to storage pitcher and makes heat exchange between flue gas and storage pitcher. Through exchange, the fuel gas will flow into again into the casing which layouts in the outside of biogas tank which shows in Figure 2. The entrance of fuel gas layer is above the biogas tank, the export is below, which is conducive to biogas tank insulation.

Due to the significantly higher rate of gas production of biogas tanks on the ground, so using biogas tanks on the ground can take full advantage of the boreal summer temperatures on the tank for heating. After winter, countryside stops using stoves. At this time, the fuel gas heat recovery system closes. The fuel gas pipeline is equivalent to an insulation layer to reduce the gas tank heat exchange with the outside.

\subsection{Energy Calculation of Heating System}

It is researched that a $3 \mathrm{~m}^{3}$ biogas tank can meet the daily life demand of a family with 4 members. This system is proposed to design biogas system to meet the demand of 100 families. So the diameter of biogas tank in this system is $\mathrm{D}=5 \mathrm{~m}$, tank height is $\mathrm{H}=4 \mathrm{~m}$, tank volume is $314 \mathrm{~m}^{3}$ and it is assumed that the outside tank smoke temperature remains at $30{ }^{\circ} \mathrm{C}$.

Heat loss of biogas $\mathrm{Q}_{\text {sum }}=\mathrm{Q}_{\text {top }}+\mathrm{Q}_{\text {bottom }}+\mathrm{Q}_{\text {side }}$; top and bottom heat loss of biogas is $\mathrm{Q}_{\text {upper }}$, $\mathrm{Q}_{\text {bottom }}$;

Multi-layer wall heat transfer coefficient k can be calculated by the following formula:

$$
K=\frac{1}{\frac{1}{h_{1}}+\sum_{i=1}^{3} \frac{\delta_{i}}{\lambda_{i}}+\frac{1}{h_{2}}}
$$

Where: $h_{1}$ : Internal convection heat transfer coefficient $h_{1}=750 \mathrm{~W} /\left(\mathrm{m}^{2} \cdot \mathrm{K}\right)$ 
$h_{2}$ Outer surface and the insulation between heat transfer coefficient, $h_{2}=6.812 \mathrm{~W} /\left(\mathrm{m}^{2} \cdot \mathrm{K}\right)$

$\lambda_{1}$ : material thermal conductivity of tank $52 \mathrm{~W} /(\mathrm{m} \cdot \mathrm{K})$;

$\lambda_{2}$ : thermal conductivity of smoke layer $0.0266 \mathrm{~W} /(\mathrm{m} \cdot \mathrm{K})$;

$\lambda_{3}$ : insulation material thermal conductivity $0.028 \mathrm{~W} /(\mathrm{m} \cdot \mathrm{K})$;

$\delta_{1}$ : tank plate thickness, $0.01 \mathrm{~m}$;

$\delta_{2}$ : insulation material thickness, $0.1 \mathrm{~m}$;

$\delta_{3}$ : protection layer thickness, $0.1 \mathrm{~m}$;

Through calculation; $K_{\text {top }}=K_{\text {bottom }}=0.3164 \mathrm{~W} /\left(\mathrm{m}^{2} \bullet \mathrm{K}\right)$

Multilayer cylindrical wall heat transfer coefficient can be calculated according to the following formula:

$$
K_{\text {side }}=\frac{1}{\frac{1}{h_{i}} \cdot \frac{d_{o}}{d_{i}}+\sum_{n=1}^{3} \frac{d_{o n}}{2 \lambda_{n}} \ln \frac{d_{o n}}{d_{i n}}+\frac{1}{h_{o}}}
$$

Through calculation $K_{\text {side }}=0.1308 \mathrm{~W} /\left(\mathrm{m}^{2} \bullet K\right)$

Thermal loss of biogas tank is:

$\mathrm{Q}=\mathrm{KA}\left(t_{1}-t_{0}\right)$

Where A :cooling area, $m^{2}$;

$\mathrm{A}_{\text {top }}=\mathrm{A}_{\text {bottom }}=20.50 \mathrm{~m}^{2} ; \mathrm{A}_{\text {side }}=64.01816 \mathrm{~m}^{2} ; K$ :thermal conductivity coefficient , $\mathrm{W} /\left(m^{2} \cdot K\right)$;

$t_{1}$ : interior substance temperature of fermentation tank, $35^{\circ} \mathrm{C}$;

$t_{0}$ : exterior environmental temperature,annual average temperature $10^{\circ} \mathrm{C}$,

The loss of bottom and upper surface of biogas tan: $\mathrm{Q}_{\text {top }}=\mathrm{Q}_{\text {bottom }}=69.905 \mathrm{~W}$;

The side loss is $\mathrm{Q}_{\text {side }}=209.087 \mathrm{~W}$

$\mathrm{Q}_{\text {sum }}=\mathrm{Q}_{\text {top }}+\mathrm{Q}_{\text {bottom }}+\mathrm{Q}_{\text {side }}=349.68 \mathrm{~W}$

Solar collectors. Vacuum tube specification: $\Phi 55 \mathrm{~mm} \times 2000 \mathrm{~mm}, 42$ pieces;

Collector area: $\mathrm{A}=0.055 \times 2 \times 42=4.62 \mathrm{~m}^{2}$;

Intensity of radiation in the north area: $\mathrm{E}=160 \mathrm{~W} / \mathrm{m}^{2}$;

Solar heating systems heat collection can be calculated according to the following formulacalculation:

$\mathrm{Q}_{\text {solar energy }}=\mathrm{AE} \eta_{\mathrm{j}}\left(1-\eta_{s}\right)$;

A:heat collection area $\left(\mathrm{m}^{2}\right)$;

E:Intensity of radiation in the north area, $\left(\mathrm{W} / \mathrm{m}^{2}\right)$;

$\eta_{\mathrm{j}}$ : heat collector efficiency, equals to 0.45 ;

$\eta_{\mathrm{s}}$ : pipeline heat loss, 0.1 ;

Heat collection quantity of solar hot water system is calculated in one day: $\mathrm{Q}_{\text {solar_enerhy }}$ $=299.38 \mathrm{~W}$;

According to the design of this system, smoke gas can provide $50 \mathrm{~W}$ heat energy for water storage tank through heat exchanger, so the external transformed total energy is: 
$\mathrm{Q}=\mathrm{Q}_{\text {solar_energy }}+\mathrm{Q}_{\text {smoke_as }}=349.376 \mathrm{~W} \approx \mathrm{Q}_{\text {sum }}=349.68 \mathrm{~W}$

External provided energy equals to the loss of biogas tank, therefore the tank temperature can remain at about $35^{\circ} \mathrm{C}$.

\section{System Benefit}

\subsection{Economic Benefit}

According to the algorithm above, without the gas insulation and solar heating systems, the gas tank's overall heat loss can be calculated: $Q_{\text {sum }}=698 \mathrm{~W}$. And this equipment can reduce the loss and it can save 6115 electricity power and will benefit 3180 yuan according to the market price of 0.52 Yuan per unit in a year.

\subsection{Enverionmental Benefit}

According to waste quantity is $24 \mathrm{~kg}$ a year per cubic meter tank, the system can break down and take advantage of $7536 \mathrm{~kg}$ waste every year which can reduce waste effectively in rural areas. And the biogas technologies conducts anaerobic fermentation of organic waste in daily life and the main gas production is methane, which is easy to use and clean and pollution-free. Besides, the fermentation residues can be used in agricultural production and is the high-class of feeds and fertilizers, and once materials are abundant and the conditions are right, it can achieve sustained production. Although the structure of energy consumption in rural areas has changed, but cooking is still the main assumption in the rural household which accounts for $40 \% \sim 60 \%$ per cent of whole household energy. Biogas, with high heating rate, has replaced straw, firewood and coal to be the main fuel for daily life which can reduce CO2 emissions, clean indoor and outdoor air and reduce the rate of rural residents suffering from respiratory diseases.

\section{References}

[1] XUE Xiaogang, LI Xiufeng, Study on the Influencing of the Rural Biogas Development in China[J], Journal of Anhui Agricultural Sciences, 2008 36(7); 2888-2890;

[2] Meng Chenglin, Li Rongping, Li Xiujin, Integrated system of greenhouse and solar heater for anaerobic digestion of excess activated sludge[J], Transactions of the Chinese society of agricultural engineeing, 2009,25(9).

[3] Kou Wei ,Zhang Lei, Qu Jingxia, Shao Lijie, et al. Engineering design of solar and power waste energy heating system for biogas project[J] Transactions of the Chinese Society of Agricultural Engineering 2013,29(24). 